\title{
ELABORAÇÃO DE BEBIDA ALCOÓLICA FERMENTADA A PARTIR DO SUCO DE MANGA ROSA (MANGIFERA INDICA L.)
}

\section{PREPARATION OF ALCOHOLIC BEVERAGE FERMENTED FROM THE JUICE OF BOUNTY MANGO (MANGIFERA INDICA $L$.)}

\author{
Natácia da Silva e Silva ${ }^{1}$; Bruna Almeida da Silva ${ }^{1}$; João Hamilton Pinheiro de Souza ${ }^{2}$; Vanderson \\ Vasconcelos Dantas ${ }^{3}$; Kledson Batista dos Reis ${ }^{4}$; Elen Vanessa Costa da Silva ${ }^{5}$ \\ ${ }^{1}$ Universidade Federal do Pará - UFPA - Belém - PA- Brasil nataciassilva@yahoo.com.br \\ 2,3,4,5 Universidade do Estado do Pará - UEPA - Belém - PA- Brasil elen@ uepa.br
}

\begin{abstract}
Resumo
O Brasil é um dos países com maior produção mundial de frutas, entretanto, há um grande desperdício pós-colheita dentre elas a manga, o que gera prejuízos. O objetivo desse trabalho foi elaborar bebida alcoólica fermentada a partir do suco de manga rosa e avaliar a aceitação. A fermentação foi realizada a temperatura ambiente, utilizando levedura Saccharomyces cerevisiae, a bebida teve acompanhamento diário das análises de acidez, ${ }^{\circ}$ Brix e $\mathrm{pH}$. Após a fermentação a bebida foi decantada por 24 horas a $5{ }^{\circ} \mathrm{C} \pm 2{ }^{\circ} \mathrm{C}$, em seguida foi filtrada, caramelizada $e$ engarrafada. Foi realizada análises de densidade, teor alcoólico e carotenóides, tendo seus valores de $0,989{ }^{\circ} \mathrm{GL}, 7,6{ }^{\circ} \mathrm{GL}$ e 9,82mg $l^{-1}$, respectivamente. A análise sensorial obteve um índice de aceitação de 96,87\%, mostrando que ofermentado de manga foi bem aceito, podendo ser uma nova alternativa para introdução da mesma no mercado de bebida alcoólica.
\end{abstract}

Palavras - chave: Mangífera indica; bebida fermentada; Saccharomyces cerevisiae.

\section{Introdução}

Devido ao sabor, características nutritivas e funcionais da manga, a mangicultura tem ganhado importância econômica, estando entre as dez culturas mais cultivadas no mundo, em aproximadamente 94 países. Devido ao clima propício, a cultura da manga se apresenta como uma das principais culturas nas regiões tropicais (MATOS, 2000).

A manga é uma das frutas mais apreciadas no mundo, sendo consumida principalmente ao natural ou ainda transformada em inúmeros produtos, como polpa simples, sucos, sorvetes, compotas, produtos congelados, desidratados, liofilizados, molhos, doces, cosméticos, bebidas fermentadas e destiladas (FONSECA et al, 2006) . Os principais produtores de manga no Brasil são os estados de São Paulo, Bahia, Rio Grande do Sul, Minas Gerais, Santa Catarina, Pará, Paraná, 
Espírito Santo, Pernambuco e Ceará, que juntos são responsáveis por $90 \%$ da produção nacional (BELING et al, 2004; DIAS et al, 2003).

A manga é constituída principalmente por água, carboidratos, ácidos orgânicos, sais minerais, proteínas, vitaminas e pigmentos. A água encontra-se em maior proporção nas frutas verdes, mas à medida que amadurecem tende a reduzir; os carboidratos, que também se encontram em elevadas proporções na composição da manga, são formados por amido, açúcares, celulose, pectina e tanino (MANICA et al, 2001).

O principal valor nutricional da manga está no seu conteúdo vitamínico constituído pelas vitaminas $B_{1}, B_{2}, C$ e $A$. Em virtude do alto teor de vitamina $A$, a manga é um excelente reservatório de antioxidante para o organismo. Esta fruta é uma fonte de caroteno, precursor da vitamina A, sendo os pigmentos carotenóides amarelos formados durante o amadurecimento e atingindo o valor máximo em frutos maduros. O beta caroteno é considerado o melhor combatente dos radicais livres (PEREIRA et al, 2005; RIBEIRO, 1997).

O Brasil é o terceiro maior produtor mundial de frutas, com uma produção que supera os 41 milhões de toneladas, perdendo apenas para China e Índia (ANUÁRIO, 2008).

Apesar de toda tecnologia já aplicada nas indústrias de frutas, ainda existe a necessidade de se desenvolver novos processamentos que permitam a redução das perdas, provenientes dos excedentes de safras, ao mesmo tempo em que agrega valor a essas frutas por meio de seu beneficiamento. As bebidas fermentadas de frutas constituem produtos promissores, além de contribuir para a redução de perdas pós-colheita de frutos perecíveis (SANDHU e JOSHI, 1995; DIAS et al, 2003).

Bebida fermentada de frutas é definida como uma bebida com graduação alcoólica de quatro a quatorze por cento em volume, a vinte graus Celsius, obtida da fermentação alcoólica do mosto de fruta sã, fresca e madura. Esse trabalho teve como objetivo obter bebida alcoólica fermentada a partir do suco de manga rosa (Mangífera indica L.), determinar suas características físico-químicas e sensoriais.

\section{Material e métodos}

\section{Material}

Foram utilizados para elaboração deste trabalho Manga Rosa (Mangífera indica), sacarose refinada especial da marca UNIÃO, fermento biológico seco (Saccharomyces cerevisiae) da marca 
SAF-INSTANT, metabissulfito de sódio da marca oxidial com 99\% de pureza, hipoclorito de sódio (concentração 10\%) industrializada por VETEC Química Fina LTDA.

\section{Processamento da bebida alcoólica fermentada}

As mangas selecionadas em estádio de maturação completa foram lavadas em água corrente. $\mathrm{Na}$ etapa de sanitização, as frutas foram imersas em solução contendo 40 litros de água a temperatura ambiente a 5 ppm (cloro a 10\%) por 20 minutos, logo após foram enxaguadas com água destilada para remoção do excesso de cloro. As mangas foram descascadas manualmente e cortadas em cubos para facilitar o despolpamento.

A extração da polpa foi em liquidificador industrial para obter um purê homogêneo, e em seguida filtrada, obtendo o mosto em volume de 10 litros. O mosto foi corrigido segundo os teores de sólidos solúveis totais ( ${ }^{\circ}$ Brix) para $17^{\circ}$ Brix.

Para o preparo do pé-de-cuba foi retirado $10 \%$ do mosto e pasteurizado a $60{ }^{\circ} \mathrm{C}$ por 30 minutos, seguido de resfriamento a $25{ }^{\circ} \mathrm{C}$. O fermento biológico seco foi adicionado na concentração de $200 \mathrm{mg} \mathrm{L}^{-1}$ e mantido em repouso em temperatura ambiente por 24 horas.

O mosto passou por processo de sulfitagem, com adição de metabissulfito de sódio na concentração de $200 \mathrm{mg} \mathrm{L}^{-1}$, para a redução da carga microbiana e reações oxidativas indesejáveis.

A fermentação ocorreu em recipiente fechado de 20 litros, adaptado para a liberação do gás carbônico e mantido em temperatura ambiente, entre $25^{\circ} \mathrm{C}$ à $30{ }^{\circ} \mathrm{C}$, durante 10 dias, até que o ${ }^{\circ}$ Brix fosse constante. Ao término da fermentação, a bebida foi colocada em câmara de refrigeração sob temperatura de $5{ }^{\circ} \mathrm{C} \pm 2{ }^{\circ} \mathrm{C}$ durante 24 horas, para facilitar a decantação da levedura, por serem menos solúveis a baixas temperaturas.

Finalizado o processo de decantação, o fermentado foi separado da borra, sem aeração, e filtrado para remoção de partículas indesejáveis, obtendo uma bebida límpida.

Para conseguir um sabor agradável foi adicionado $100 \mathrm{~g}$ de açúcar caramelizado em $50 \%$ do volume total obtido da bebida. A bebida foi engarrafada em frascos de vidro de $180 \mathrm{ml} \mathrm{e}$ armazenadas em temperatura ambiente $30^{\circ} \mathrm{C} \pm 5$.

\section{Análises físico-químicas}

O fermentado foi analisado quanto aos teores de sólidos solúveis totais ( $\left.{ }^{\circ} \mathrm{Brix}\right), \mathrm{pH}$ e acidez total titulável, a cada 24 horas, segundo Instituto Adolfo Lutz (2008).

As análises de densidade e teor alcoólico foram determinadas segundo a Portaria $n^{\circ} 76$ de 26 de novembro de 1986 que dispõe sobre os métodos analíticos de bebidas e vinagre Ministério da 
Agricultura Pecuária e Abastecimento (BRASIL, 1986). A determinação de carotenóides totais por extração e quantificação foi realizada segundo Rogriguez-Amaya (1999).

\section{Análise sensorial}

Os testes de análise sensorial foram realizados com 40 provadores não treinados, de ambos os sexos e idade variada. A bebida foi avaliada quanto à aceitação, através de escala hedônica estruturada de nove pontos ( 9 = gostei muitíssimo; 1 = desgostei muitíssimo) e intenção de compra, escala estruturada de cinco pontos $(1=$ certamente não compraria; $5=$ certamente compraria) (STONE e SIDEL, 1993).

\section{Análises dos dados}

As análises físico-químicas foram realizadas em triplicatas, e a partir dos valores obtidos foram realizadas as médias e desvio padrão.

\section{Resultados e discussão}

\section{Fermentado de manga rosa}

O valor inicial de sólidos solúveis totais da bebida alcoólica fermentada de manga foi de 17 $\pm 0,07^{\circ}$ Brix e o final foi $5,5 \pm 0,05^{\circ}$ Brix, o $\mathrm{pH}$ final foi 3,4 $\pm 0,56$, o teor alcoólico de 7,6 $\pm 0,06 \mathrm{e}$ a acidez total titulável foi $3,7 \pm 0,34$.

Os teores de sólidos solúveis totais, $\mathrm{pH}$, teor alcoólico, acidez total titulável estão apresentados na tabela 1 .

Tabela 1- Valores observados no final da fermentação

\begin{tabular}{cccccc}
\hline${ }^{\mathbf{0}}$ Brix inicial & $\begin{array}{c}{ }^{\mathbf{0}} \text { Brix } \\
\text { final }\end{array}$ & $\mathbf{p H}$ & Teor Alcoólico & $\begin{array}{c}\text { Acidez Total } \\
\text { Titulável \% }\end{array}$ & $\begin{array}{c}\text { Dias de } \\
\text { Fermentação }\end{array}$ \\
\hline $17 \pm 0,07$ & $5,5 \pm 0,05$ & $3,4 \pm 0,56$ & $7,6 \pm 0,06$ & $3,7 \pm 0,34$ & 10 \\
\hline
\end{tabular}

$\mathrm{O}$ pH e a acidez são considerados importantes para a estabilidade biológica das bebidas alcoólicas fermentadas de frutas, e o etanol produzido durante o processo de fermentação alcoólica também contribuiu para obtenção desta estabilidade.

O teor alcoólico obtido foi de 7,6, que a classificada como fermentado de fruta, segundo o Decreto n. 2.314, de 04 de Setembro de 1997, que dispõe sobre a padronização, a classificação, o 
registro, a inspeção, a produção e a fiscalização de bebidas, cujo teor alcoólico mínimo é de $4 \%$ e o máximo de $14 \%$.

A figura 1 mostra a concentração de sólidos solúveis totais $\left({ }^{\circ}\right.$ Brix $)$ do mosto durante ao período de fermentação.

Figura 1- Sólidos solúveis totais em mosto de manga rosa durante a fermentação

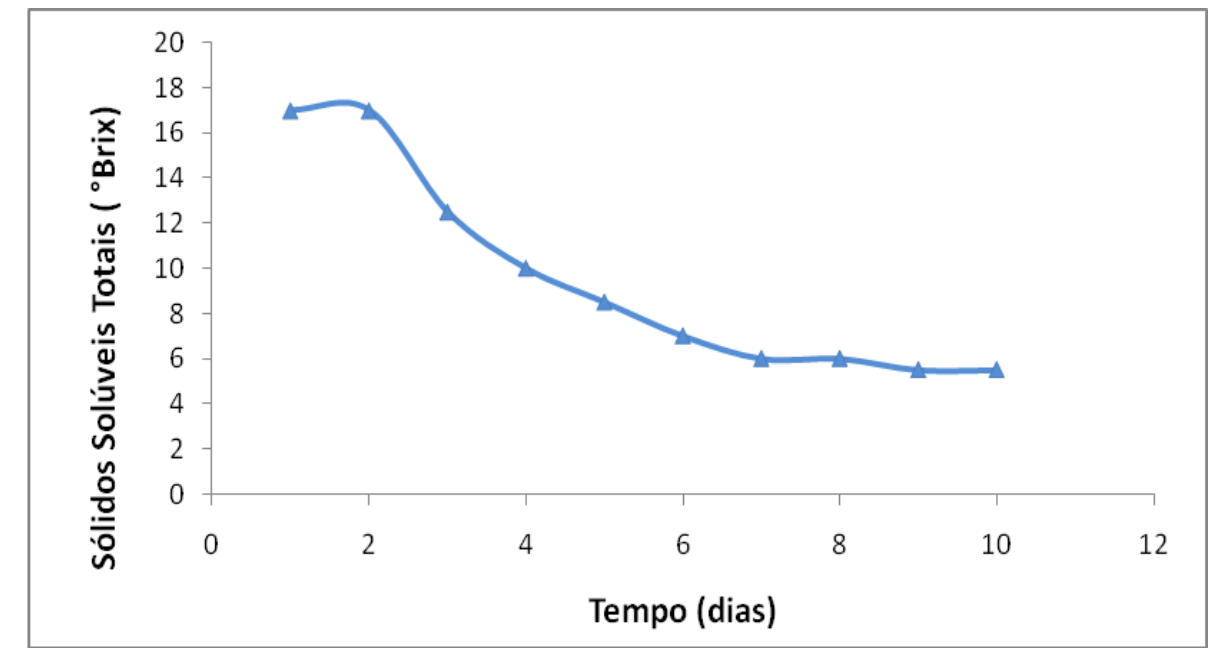

O teor de sólidos solúveis totais nos dois primeiros dias permaneceu constante, este fato sugere ter sido a presença de metabissulfito de sódio, utilizado na sulfitagem, para a adaptação das leveduras no meio.

Segundo AQUARONE et al (1993) após a fase de adaptação as Sacarromyses cerevisae começam a atuar consumindo diariamente os açucares, ocorrendo assim à conversão de açúcar em etanol e gás carbônico, promovendo uma diminuição da concentração inicial de sólidos solúveis.

$\mathrm{Na}$ bebida alcoólica fermentada de manga o teor de sólidos solúvel total inicial de $17{ }^{\circ} \mathrm{Brix}$ diminuiu, atingindo o valor final de 5,5 no período de 10 dias. $\mathrm{O}$ valor final do ${ }^{\circ}$ Brix permaneceu constante indicando o fim da fermentação.

$\mathrm{O}$ aumento da acidez e conseqüentemente a redução do $\mathrm{pH}$ ao longo do processo fermentativo, são decorrentes da produção de ácidos orgânicos (BORZANI et al, 1983). A faixa de $\mathrm{pH}$ de 5,6 a 3,4, durante o processo fermentativo foi suficiente para permitir uma rápida fermentação alcoólica.

RIZZON et al (1994) ressaltam que a variação na acidez durante a fermentação tem grande influência na estabilidade e coloração das bebidas fermentadas, pois quando o meio torna-se ácido a probabilidade de ocorrer contaminação microbiana é mínima, visto que a maioria dos microrganismos prefere meios básicos ou alcalinos. 
O comportamento do pH e da acidez estão representados na Figura 2. Esses parâmetros estão correlacionados, visto que quando os valores de $\mathrm{pH}$ diminuem a acidez do mosto aumenta (BORZANI et al, 1983).

Figura 2 - Comportamento do pH e da acidez em função do tempo de fermentação

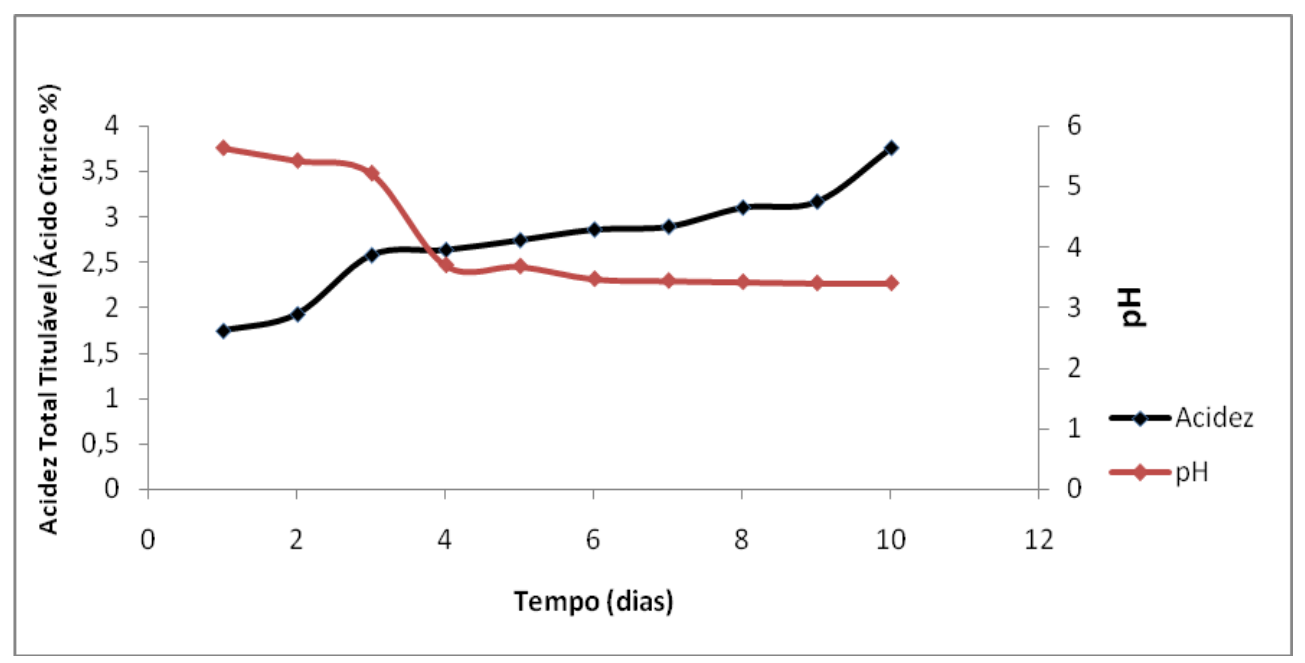

Bebida alcoólica fermentada de manga

Tabela 2 - Resultados das análises físico-químicas da bebida alcoólica fermentada de manga

\begin{tabular}{lc}
\hline Análises & Valores Obtidos \\
\hline $\mathrm{pH}$ & $3,4 \pm 0,56$ \\
Acidez Titulável Total (\%) & $3,7 \pm 0,34$ \\
Teor alcoólico $\left({ }^{\circ} \mathrm{GL}\right)$ & $7,6 \pm 0,06$ \\
Sólidos solúveis totais & $5,5 \pm 0,05$ \\
Densidade $\left({ }^{\circ} \mathrm{GL}\right)$ & $0,989 \pm 0,08$ \\
Carotenóides & $9,82 \pm 0,26$ \\
\hline
\end{tabular}

$\mathrm{O}$ resultado referente ao $\mathrm{pH}$, apresentado na Tabela 2 , indicou que a bebida alcoólica fermentada de manga rosa possui maior resistência as contaminações microbianas, visto que o fermentado apresenta $\mathrm{pH}$ ácido. A legislação vigente não apresenta padrão para esta análise.

A determinação de acidez total titulável, possibilita obter informações sobre alterações indesejáveis que possa a vir a ocorrer na bebida alcoólica fermentada.

O valor do teor alcoólico observado na Tabela 2,encontra-se dentro dos limites estabelecidos para os fermentados de frutas, de acordo com o Decreto n. 2.314, de 04 de Setembro de 1997.

A análise de carotenóides foi realizada na fruta in natura e na bebida alcoólica fermenta de manga. Na fruta in natura o valor obtido foi de $28,00 \mu \mathrm{g} / \mathrm{L}$ e na bebida de 9,82 $\mu \mathrm{g} / \mathrm{L}$, tendo assim, uma redução dos carotenóides, esta diminuição pode ser devido ao processo de pasteurização 
realizada no pé-de-cuba, visto que o aumento da temperatura afeta a quantidade de carotenos, pois esses pigmentos são sensíveis a temperaturas elevadas (MACHADO et al, 2006).

\section{Teste sensorial}

Os resultados de teste de aceitabilidade utilizando a escala hedônica e intenção de compra para a avaliação da bebida alcoólica fermentada do suco de manga estão apresentados nas tabelas 3 e 4 .

Tabela 3 - Análise sensorial da aceitabilidade segundo as características organolépticas

\begin{tabular}{lc}
\hline Bebida alcoólica fermentada de manga & Aceitabilidade \\
\hline Cor & $68,44 \%$ \\
Aroma & $70,33 \%$ \\
Sabor & $74,00 \%$ \\
Textura & $66,66 \%$ \\
Impressão global & $82,22 \%$ \\
\hline
\end{tabular}

De acordo com os resultados obtidos, Tabela 3, houve boa aceitabilidade da bebida alcoólica fermentada de manga, em relação à cor, aroma, sabor, textura e impressão global.

A bebida obteve coloração característica da fruta, decorrente do processo de sulfitagem e pelo emprego do metabissulfito de sódio por ser um agente antioxidante manteve a cor natural da fruta. A bebida apresentou aroma agradável, possivelmente devido a formação de compostos voláteis como o etanol. O sabor apresentou $74 \%$ de aceitabilidade e a textura obteve o menor índice de aceitabilidade comparado com os outros atributos.

A bebida alcoólica fermentada de manga obteve índice de aceitabilidade de 96,87\%, essa boa aceitabilidade, pode ser devido a adição de açúcar caramelizado, proporcionando um sabor levemente adocicado, contribuindo assim para um bom índice de aceitação. Esta aceitabilidade foi superior ao encontrado por SANTOS e OLIVEIRAS (2007) de 79,55\% em fermentado de abacaxi e de $80 \%$ encontrado na bebida alcoólica de pupunha por PANTOJA et al (2001).

A Tabela 4 apresenta o teste de intenção de compra da bebida alcoólica fermentada de manga.

Tabela 4 Intenção de compra (\%) da bebida alcoólica fermentada de manga

\begin{tabular}{lc}
\hline Discriminação & $\mathbf{( \% )}$ \\
\hline Certamente compraria & 33,33 \\
Provavelmente compraria & 43,33 \\
Tenho duvidas se compraria & 23,33 \\
Provavelmente não compraria & 0,00 \\
Certamente não compraria & 0,00 \\
\hline
\end{tabular}


A maior porcentagem de intenção de compra foi provavelmente compraria, este valor estar relacionado a viscosidade obtida na bebida alcoólica fermentada de manga, em decorrência da manga ser uma fruta fibrosa.

Os valores entre os sólidos solúveis totais $\left({ }^{\circ}\right.$ Brix) da bebida fermentada de manga e outras bebidas fermentadas podem ser observados a partir da Tabela 5.

A bebida alcoólica fermentada de manga apresentou um ${ }^{\circ}$ Brix de 5,50 $\pm 0,05$.

Tabela 5 - Comparação dos valores de sólidos solúveis totais ( ${ }^{\circ}$ Brix) do fermentado de manga com outros fermentados de frutas

\begin{tabular}{lc}
\hline Fermentado & Sólidos Solúveis Totais ( ${ }^{\mathbf{B}}$ Brix) \\
\hline Manga & 5,50 \\
\hline Mandacaru (Almeida et al, 2006) & 5,50 \\
Maça (Barwal, 1991) & 6,00 \\
Banana (Arruda et al ,2003 & 6,00 \\
\hline
\end{tabular}

Comparando os sólidos solúveis totais ( $\left.{ }^{\circ} \mathrm{Brix}\right)$ da bebida alcoólica fermentada de manga, com os fermentados de mandacaru apresentado por ALMEIDA et al (2006), maçã por BARWAL (1991) e banana por ARRUDA et al (2003), foi verificado proximidade nas concentrações de sólidos solúveis totais, este fato pode ser devido a correção inicial do ${ }^{\circ}$ Brix realizado nos fermentados.

A análise de sólidos solúveis totais não é sugerida pelo Decreto n. 2.314, de 04 de Setembro de 1997, porém, necessária, pois pode indicar o término da fermentação.

A Tabela 6 apresenta os valores de $\mathrm{pH}$ da bebida alcoólica fermentada de manga e outras bebidas fermentadas de frutas.

A bebida alcoólica fermentada de manga apresentou um $\mathrm{pH}$ de 3,4 $\pm 0,56$.

Tabela 6 - Comparação do pH do fermentado de manga com outros fermentados

\begin{tabular}{lc}
\hline Fermentado & pH \\
\hline Manga & 3,40 \\
Laranja (Corazza et al, 2001) & 3,30 \\
Figo (Lopes e Silva, 2006) & 3,50 \\
Taperebá (Mendonça e Port's, 2007) & 3,20 \\
Acerola (Santos et al, 2005) & 3,00 \\
Mandacaru (Almeida et al, 2006) & 3,80 \\
Abacaxi (Santos e Oliveira, 2007) & 5,40 \\
\hline
\end{tabular}

Comparando o $\mathrm{pH}$ do fermentado de manga com os fermentados de laranja CORAZZA et al (2001), figo LOPES e SILVA (2006), taperebá MENDONÇA e PORT’S (2007) e mandacaru ALMEIDA et al (2006), observa-se que os valores obtidos foram aproximados, sendo estes desejáveis para bebidas alcoólicas fermentadas, de acordo com o Decreto n. 2.314, de 04 de 
Setembro de 1997. Em relação ao fermentado de acerola desenvolvido por SANTOS et al (2005) obtiveram um menor valor em decorrência do mosto ter sido corrigido com adição de carbonato de cálcio, levando-o a um pH final de 3,0. No entanto, no fermentado de acerola quanto o de manga obtiveram um $\mathrm{pH}$ satisfatório aumentando sua estabilidade biológica. O fermentado de abacaxi desenvolvido por SANTOS e OLIVEIRA (2007), apresentou um pH elevado, decorrente do crescimento de microrganismo indesejáveis durante a fermentação.

Segundo SATON et al (2000) o pH médio de 3,5 confere maior resistência aos principais microrganismos responsáveis pelas alterações em fermentados de frutas. $\mathrm{O}$ pH obtido na bebida alcoólica fermentado de manga foi menor que 3,5.

O resultado da acidez total titulável do fermentado de manga rosa foi 3,7 $\pm 0,34$ observado na Tabela 2, pode ser comparado com o valor encontrado por SANTOS et al (2005) que obtiveram 3,8 e o fermentado de figo-da-índia LOPES e SILVA (2006), que obtiveram 4,5.

O teor alcoólico apresentou valor médio de 7,6 $\pm 0,06$, observado na Tabela 2, comparado com o fermentado do figo-da-índia de $6,05^{\circ} \mathrm{GL}$ produzido por LOPES e SILVA (2006) e, ARRUDA et al (2003), obteve $8,9^{\circ} \mathrm{GL}$ em fermentado de banana. Os valores semelhantes podem ser devido as mesmas condições de fermentação, como microrganismos, ${ }^{\circ}$ Brix iniciais do mosto, temperatura de armazenamento (ambiente), período de fermentação e pH.

O fermentado de manga obteve menor densidade $\left(0,989^{\circ} \mathrm{GL} \pm 0,08\right)$ comparado com os trabalhos desenvolvidos por CALDAS et al (2006) que obtiveram $1,147^{\circ} \mathrm{GL}$ e SANTOS e OLIVEIRA (2007) que obtiveram $1,033^{\circ} \mathrm{GL}$. Esta menor densidade é em decorrência do processo de filtração realizado na polpa e na bebida já fermentada, esta análise não é sugerida pela legislação. A Tabela 7 compara os valores de carotenóides presentes na polpa do fruto de manga com outros frutos.

Tabela 7 - Teor de carotenóides em manga e outros frutos

\begin{tabular}{lc}
\hline Frutas & Resultados $(\boldsymbol{\mu g} / \mathbf{g})$ \\
\hline Manga & 28,00 \\
Cajá (Mattietto, 2005) & 28,30 \\
Taperebá (Mendonça e Port's, 2007) & 9,67 \\
\hline
\end{tabular}

Os resultados de carotenóides da polpa da manga foram semelhantes com os encontrados por MATTIETTO (2005) em polpa de cajá e diferente do encontrado por MENDONÇA e PORT'S (2007), essa diferença pode estar relacionada ao período de safra e dos aspectos climáticos da região onde foram colhidos. 


\title{
4. Conclusão
}

O processo fermentativo da bebida ocorreu durante um período de 10 dias, sendo o ${ }^{\circ}$ Brix inicial de $17 \pm 0,07$ e o final 5,5 $\pm 0,05$, ocorrendo assim a diminuição de açucares durante processo fermentativo, e o teor alcoólico obtido foi 7,6, estando assim dentro do que preconiza a legislação para bebida fermentada de fruta.

Os valores encontrados a partir das análises de $\mathrm{pH}$ e acidez da bebida alcoólica fermenta foi de 3,4 \pm 0,56 e 3,7 $\pm 0,34$ respectivamente, estes valores proporcionaram a bebida alcoólica fermentada de manga maior estabilidade em relação as alterações indesejáveis.

De acordo com a análise sensorial a bebida alcoólica fermentada indicou uma boa aceitabilidade, sendo os maiores valores obtidos foi em relação ao sabor e aroma de 70,33\% e $74,00 \%$ respectivamente, e o indicie de aceitação da bebida foi de 96,87\%, sendo assim, esta tecnologia pode ser uma das alternativas para a utilização desta fruta na elaboração de uma nova bebida fermentada.

\begin{abstract}
Brazil is a country with higher global production of fruits, however, there is a large post-harvest waste among them the manga, which generates losses. The aim of this study was to develop alcoholic beverage fermented from the juice of mango and pink assess acceptance. The fermentation was performed at room temperature, using yeast Saccharomyces cerevisiae, the drink had daily monitoring of the tests for acidity, ${ }^{\circ}$ Brix and $\mathrm{pH}$. After proving the drink was decanted for 24 hours at $5^{\circ} \mathrm{C} \pm 2{ }^{\circ} \mathrm{C}$, then was filtered, bottled and caramelized. We performed analysis of density, alcohol content and carotenoids and their values of $0.989^{\circ} \mathrm{GL}, 7.6^{\circ} \mathrm{GL}$ and $9.82 \mathrm{mg} / \mathrm{l}$, respectively. Sensory analysis obtained an acceptance rate of $96.87 \%$, showing that the fermented mango was well accepted and may be a new alternative for the market introduction of the same liquor.
\end{abstract}

Key-words: Mangífera indica; brew; Saccharomyces cerevisiae.

\section{Referências}

ALMEIDA, M. M.; TAVARES, D. P. S. A.; ROCHA, A. S.; OliVEIRA, L. S. C.; SILVA, F. L. H.; MOTA, J. C. Cinética da produção do fermentado do fruto do mandacaru. Revista Brasileira de Produtos Agroindustriais, Campina Grande, v.82, n. 01, p.35-42, 2006.

ANUÁRIO BRASILEIRO DE FRUTICULTURA, 2008. Editora Gazeta, 2008. 136 p.

AQUARONE, E; LIMA, U. A.; BORZANI, W. Alimentos e bebidas produzidos por fermentação. 4 ed. São Paulo: Edgard Blugher Ltda., 1993.

ARRUDA, A. R. CASIMIRO, A. R. S. de; GARRUTI, D. S.; ABREU, F. A. P. Processamento de bebida fermentada de banana. Revista Ciência Agronômica, v.34, n. 2, 2003.

BARWAL, V. S. Low alcoholic beverages from culled apples. Journal of Food Science and Technology, India, v. 28, n.4, 1991. 
BRASIL. Decreto n. 2.314, de 04 de Setembro de 1997. Dispõe sobre a padronização, a classificação, o registro, a inspeção, a produção e a fiscalização de bebidas. Diário Oficial da República Federativa do Brasil. Brasília. DF, 5 de set.1997.

BRASIL. Ministério da Agricultura. Portaria n 76 de 26 de novembro de 1986. Dispõe sobre os métodos analíticos de bebidas e vinagre. Diário Oficial da República Federativa do Brasil. Brasília. DF, 28 de nov. 1986.

BELING, R. R. et al. (sic). Anuário Brasileiro de Fruticultura. Santa Cruz do Sul: Gazeta Santa Cruz, 2004.

BORZANI, W; AQUARONE, E; LIMA, U. A. Engenharia Bioquímica. São Paulo: Edgard Blucher, 1983.

CALDAS, M. C. S.;MANFROI, L. ; MELO NETO, B. A.; SANTOS, J. S.; NASCIMENTO, L. A.; CARVALHO, E. A.; CARVAJAL, J. C. L. Elaboração de fermentado alcoólico de abacaxi. I Jornada Nacional da Agroindústria, CEFET, Bananeiras - SP, 2006.

CORRAZA, M. L.; RODRIGUES, D. G.; NOZAKI, J. Preparação e caracterização do vinho de laranja. Química Nova, v. 24, n. 4, Maringá, 2001.

DIAS, D. R.; SCHWAN, R. F.; LIMA, L. C. O. Metodologia para elaboração de fermentado de cajá (Spondias mombin L. ). Ciências e Tecnologia de alimentos, Campinas, v. 23, n. 3, 2003.D.O.I 10.1590/S0101-20612003000300008

FOnSECA, N.; CUNHA, G. A. P.; NASCIMENTO, A. S.; FILHO, H. P. S. A Cultura da Manga. 2.ed. Brasília: Embrapa, 2006. 63p.

INSTITUTO ADOLFO LUTZ. Métodos físico-químicos para análise de alimentos. São Paulo: Instituto Adolfo Lutz, 2008 .

LOPES, R. V; SILVA, F. L. H. Elaboração de fermentado a partir do figo-da-india Revista de Biologia e Ciências da Terra. v. 6, n. 2, 2006.

MACHADO,C. M. M.; MORETTI, C. L.; SOUSA, R. M. D. Aproveitamento das raspas geradas na produção de minicenouras. ComunicadoTécnico, Brasília, DF, 2006.

MANICA, I; MALAVOLTA E; ICUMA, I.M; CUNHA, M.M; JUNIOR, M. E. O; JUNQUEIRA, N. T. V; RAMOS, V. H. V. MANGA: tecnologia, produção, pós-colheita, agroindústria e exportação. Porto Alegre: Cinco Continentes, 2001.

MATtIETTO, R. de A. Estudo Tecnológico de um néctar misto de cajá (Spondias lútea L.) e umbu (Spondias tuberosa, Arruda Camara). 2005. 299 f, Tese (Doutorado em Tecnologia de Alimentos)- Faculdade de Engenharia de Alimentos,Universidade Estadual de Campinas, Campinas-SP, 2005.

MATOS, A. P. Manga: produção. Brasília: EMBRAPA, 2000. (Comunicação para transferência de tecnologia. Frutas do Brasil).

MENDONÇA, A. P e PORT'S, P. S. Vinho de taperebá (Spondias lútea L.) 2007. Trabalho de Conclusão de Curso, (Graduação em Tecnologia Agroindustrial ) Universidade do Estado do Pará, Centro de Ciências Naturais e Tecnologia, Paragominas, 2007.

PANTOJA, O. L.; MAEDA, R.; ANDRADE, J. S.; PEREIRA JR., N.; CARVALHO, S. M. S; ASTOLFI FILHO, S. Processamento fermentativo para produção de bebida alcoólica de pupunha (Bactris gasipaes Kunth). Biotecnologia Ciência e Desenvolvimento. v 3, n.19, 2001.

PEREIRA, M. E. C; FONSECA, N; SOUZA, F. V. D. MANGA: o produtor pergunta, a Embrapa responde. Brasília: Embrapa, 2005.

RIBEIRO,I. J. A. Doenças da Mangueira. In: KIMATI, H; AMORIM, L; BERGAMIN F. A; CAMARGO, L. E. A; REZENDE, J. A. M. Manual de Fitopatologia. 3 Ed. v. 2. Doenças das plantas cultivadas. São Paulo: Agronômica Ceres Ltda, 1997. 
RIZZON, L. A.; ZANIUZ, M. C.; MANFREDINI, S. Como Elaborar Vinho de Qualidade na Pequena Propriedade. Bento Gonçalves: Embrapa, 1994.

RODRIGUES- AMAYA, D.B. A guide to carotenoid analysis in food. Washington: ILSI Press, 1999.

SANDHU, D. K; JOSHI, V. K. Technology, quality and scope of fruitwines especialiy Apple beverages. Indian Food Industry, v.14, n.1, 1995.

SANTOS, G.; OLIVEIRA, M. A. X. Elaboração e Processamento de bebida alcoólica fermentada, a partir do suco do abacaxi (Ananas comosus, L. Merril), produzido no Município de Floresta do Araguaia).2007. Trabalho de Conclusão de Curso (Graduação em Tecnologia Agroindustrial ) Universidade do Estado do Pará, Centro de Ciências e Tecnologia , Redenção, 2007.

SANTOS, S.C. ; ALMEIDA, S. S.; TOLEDO, A. L.; SANTANA, J. C. C.; SOUZA, R. R. Elaboração e Análise Sensorial do Fermentado de Acerola (Malpighia punicifolia L.).Brazilian Journal of food Technology. $5^{\circ}$ Sipal, 2005.

SALTON, M. A.; DAUDT, C. E.; RIZZON, L. A. Influência do dióxido de enxofre e cultivares de videira na formação de alguns compostos voláteis e na qualidade sensorial do destilado de vinho. Ciência e tecnologia de alimentos. v. 20 , n. 3, 2000. D.O.I: 10.1590/S0101-20612000000300005

STONE, H. S.; SIDEL, J. L. Sensory Evaluation Practies. 2 Ed. San Diego: Academic Press, 1993. 338 p.

Submetido em 03 mai 2010; Revisão recebida dos autores em 16 nov. 2010; Aceito para publicação em 30 jun.2011. 